Sharif University of Technology
Scientia Iranica
SCIENTIA
I RAN ICA
http://scientiairanica.sharif.edu

\title{
Prediction of uplift capacity of suction caisson in clay using functional network and multivariate adaptive regression spline
}

\author{
S. Bhattacharya, P. Murakonda, and S. Kumar Das* \\ Department of Civil Engineering, National Institute of Technology, Rourkela, 769008, India.
}

Received 16 October 2015; received in revised form 19 October 2016; accepted 28 January 2017
KEYWORDS
Suction caisson;
Uplift capacity;
Functional network;
Multivariate adaptive
regression spline;
Artificial intelligence;
Statistical
performances.

\begin{abstract}
Suction caissons are extensively used as anchors for offshore foundation structures. The uplift capacity of suction caisson is an important factor with respect to effective design. In this paper, two recently developed AI techniques, i.e. Functional Network (FN) and Multivariate Adaptive Regression Spline (MARS), have been used to predict the uplift capacity of suction caisson in clay. The performances of the developed models are compared with those of other AI techniques: artificial neural network, support vector machine, relevance vector machine, genetic programming, extreme learning machine, and Group Method of Data Handling with Harmony Search (GMDH-HS). The model's inputs include the aspect ratio of the caisson, undrained shear strength of soil at the depth of the caisson tip, relative depth of the lug to which the caisson force is applied, load inclination angle, and load rate parameter. The results of the above AI techniques are comparatively analysed via different statistical performance criteria: correlation coefficient $(R)$, root mean square error, Nash-Sutcliffe coefficient of efficiency, and log-normal distribution of ratio of the predicted load capacity to observed load capacity, with a ranking system to determine the best predictive model. The FN and MARS models are found to be comparably efficient which can outperform other AI techniques.
\end{abstract}

(C) 2018 Sharif University of Technology. All rights reserved.

\section{Introduction}

Suction caissons, first introduced by Senpere and Auvergne [1] as mooring anchors, are steel tubes open at the bottom and closed at the top (Figure 1). They serve as anchors by penetrating the seafloor bottom sediments. They provide greater resistance to lateral loads than driven piles due to the larger diameters generally used. Suction caissons are one

\footnotetext{
*. Corresponding author. Tel.: +919437390601 E-mail addresses: sumanab24@gmail.com (S. Bhattacharya); pavani.2230@gmail.com (P. Murakonda); saratdas@rediffmail.com (S. KumarDas)
}

doi: $10.24200 /$ sci. 2017.4192 of the most effective anchors for deep-water offshore facilities as they demand less construction time and provide efficiency for static and dynamic loads. The caisson foundation is designed for static and cyclic loads due to wind and loop currents. Due to horizontal and inclined loads, uplift force is transmitted to caisson anchors. Albert et al. contended that the total uplift capacity of caisson depends upon passive suction under caisson-sealed cap, self-weight of caisson, frictional resistance along the soil-caisson interface, submerged weight of soil plug inside the caisson and uplift soil bearing pressure [2]. Hence, suction caisson becomes more effective, particularly in clayey soil. Consequently, the uplift capacity of suction caisson is an important parameter for design consideration.

Various methods are in use to determine the 


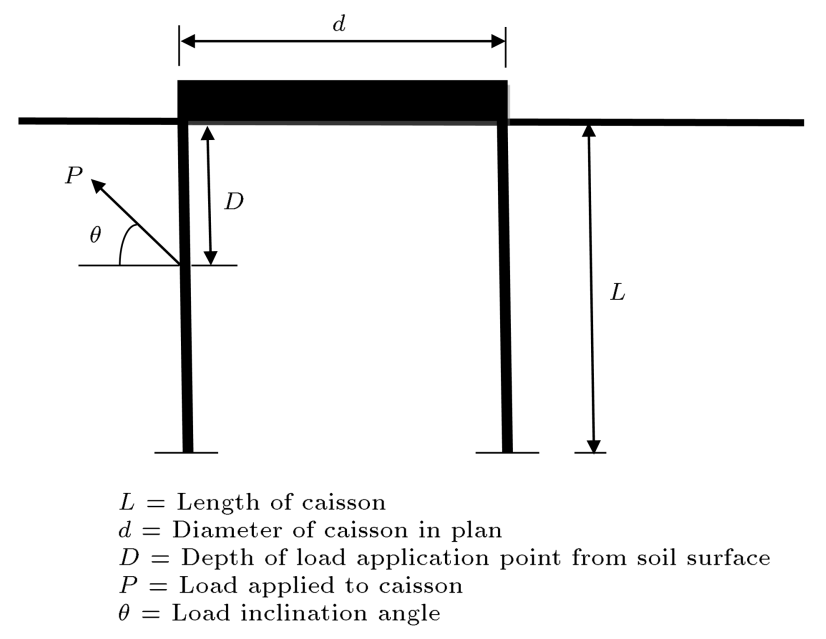

Figure 1. Definition sketch of a suction caisson.

uplift capacity of suction caisson for static and cyclic loads under different soil conditions. Upper bound analysis [3], finite-element method [4-9], laboratory model study [10-17], centrifuge model [3,18,19], and prototype model tests [20-23] have been utilized to calculate the axial and lateral load capacities of suction caisson. Theoretically, Finite-Element Method (FEM) is considered the ideal method as it is based on material properties determined using appropriate sophisticated laboratory testing and validated with the result of centrifuge test. However, spatially, there is a wide variation in soil properties. Hence, it is very difficult to develop a sufficiently accurate site model for FEM, which requires extensive site characterization effort and appropriate constitutive modelling of clayey soil. Hence, expensive, various types of field tests have been performed by Cho et al. to determine the feasibility of suction caisson in different types of soil [23].

These days, AI techniques are being used as alternate numerical simulation models in many complex civil engineering [24] and geotechnical engineering problems [25]. Rahman et al. [26] used Artificial Neural Network (ANN) model to predict the uplift capacity of suction caisson in clay. Based on statistical performance criteria and correlation coefficient $(R)$, the ANN model was found to be more efficient than the FEM model. However, Pai [27] observed that the FEM model is better, compared to genetic algorithm-based neural network model using the same database. Although it is now possible to write down a model equation based on the trained ANN parameters (weights and biases), it is considered still as a 'black box' $[25,28,29]$. The ANN is also associated with poor generalization for some complex problems, and magnitude of weight is one of its reasons [30]. Furthermore, Support Vector Machine (SVM) and Relevance Vector Machine (RVM), i.e. another group of AI techniques, are based on statistical learning theory [30,31]; they are found to be better than the ANN model for some geotechnical engineering problems [32]. In the recent past, Genetic Programming (GP), which is a biologically inspired AI method, has been used as an AI technique to model difficult geotechnical engineering problems [33-38]. Alavi et al. [39] found that a hybrid computational model (coupling of GP and simulated annealing) provided a better prediction performance than GP did, by predicting the uplift capacity of suction caisson using the above database (Rahman et al. [26]). Gandomi et al. [40] proposed a promising variant of GP, namely Multi-Expression Programming (MEP), and proved its higher capability in prediction performance compared to ANN and FEM models. Multivariate Adaptive Regression Spline (MARS), developed by Friedman [41], is a flexible regression model that fits relationships which are nearly additive and involve lesser variables. Samui et al. [42] observed that the MARS model for uplift capacity of suction caisson has better statistical performances compared to the ANN and FEM models. Cheng et al. [43] observed that fuzzy radial basis functional neural network interference model (IFRIM) has better prediction performances in comparison to FEM, Evolutionary Radial Basis Function Neural Network (ERBFNN), and Radial Basis Function Neural Network (RBFNN) for the above-mentioned problem. However, IFRIM requires long duration of computation time in order to determine the optimal parameter values in the optimization process [43]. Muduli et al. used a variant of ANN, known as Extreme Learning Machine (ELM), and found that ELM prediction model is more efficient than ANN, SVM, RVM, and GP models [44]. However, the model equation as per ELM is not very comprehensive to be used by professional engineers. Recently, Shahr-Babak et al. used Group Method of Data Handling (GMDH) with Harmony Search (HS) for the present problem and was found it to outperform the above AI techniques [45].

Most recently, FN has been introduced by Castillo et al. to overcome the drawbacks of neural networks [4648]. Castillo et al. used FNs to solve structural engineering problems such as predicting shear, moment, slope, and deflection of a beam [49]. Rajasekaran applied the functional network to structural engineering using associative functional network, and then analysed five example problems including the slope, moment, deflection of beam problem by Castillo et al. [49] using orthogonal equations [50]. Attoh-Okine applied functional network to the modelling of incremental pavement roughness [51]. In petroleum engineering, also, FN was found to be efficient for the determination of permeability in a carbonate reservoir [52]. Adeniran et al. also used associative functional network in soft sensor for formation porosity and water saturation in oil wells [53]. However, in geotechnical en gineering, the 
application of functional network is hardly available in literature. Hence, motivated by successful applications of FN in modelling non-linear system behaviors in different fields as discussed above, an attempt has been made here to use the same $\mathrm{FN}$ for the prediction of uplift capacity of suction caisson.

In the present study, an FN-based prediction model for uplift capacity $(Q)$ of suction caisson in clay is developed using the database from literature [26]. Different statistical criteria, such as correlation coefficient $(R)$, Nash-Sutcliffe coefficient of efficiency $(E)$, Root Mean Square Error (RMSE), Average Absolute Error (AAE), and Maximum Absolute Error (MAE), are used to compare the FN model with the presently developed MARS model and with GP, FEM, ANN, SVM, RVM, and ELM models as available in literature $[37,44]$. A ranking system (according to AbuFarsakh and Titi [54]) based on the following four criteria has been also used to compare different models:

(i) The best fit calculations ( $R$ and $E$ ) for predicted uplift capacity of suction caisson $\left(Q_{p}\right)$ and measured capacity $\left(Q_{m}\right)$;

(ii) Arithmetic calculations (mean $\mu$ and standard deviation $\sigma$ ) of the ratio, $Q_{p} / Q_{m}$;

(iii) $50 \%$ and $90 \%$ cumulative probabilities $\left(P_{50}\right.$ and $\left.P_{90}\right)$ of the ratio, $Q_{p} / Q_{m}$

(iv) Probability of predicting the uplift capacity within $20 \%$ accuracy level in percentage using histogram and lognormal probability distribution of $Q_{p} / Q_{m}$ [54].

\section{Multivariate adaptive regression spline}

The MARS was introduced by Friedman as a statistical model for solving regression-type problems to predict the output value of a dependent variable from a given set of independent variables [41]. MARS is a nonlinear nonparametric method based on 'divide and conquer' strategy, which partitions the input dataset into separate piecewise linear segments (splines) with its separate regression equations [55]. The partition point between the two regions is termed as 'knot'. MARS has become a very popular data mining tool as it assumes no underlying functional relationship between the input variables and output variable, and the model is constructed based on a set of coefficients and piecewise linear and nonlinear functions known as 'Basis Functions' (BF), approximating the relationship between input and output variables.

The general MARS model equation is given by:

$$
f(X)=\beta_{0}+\sum_{m=1}^{M} \beta_{m} \lambda_{m}(X),
$$

where each $\lambda_{m}$ is a basis function. $\beta_{0}$ (the intercept

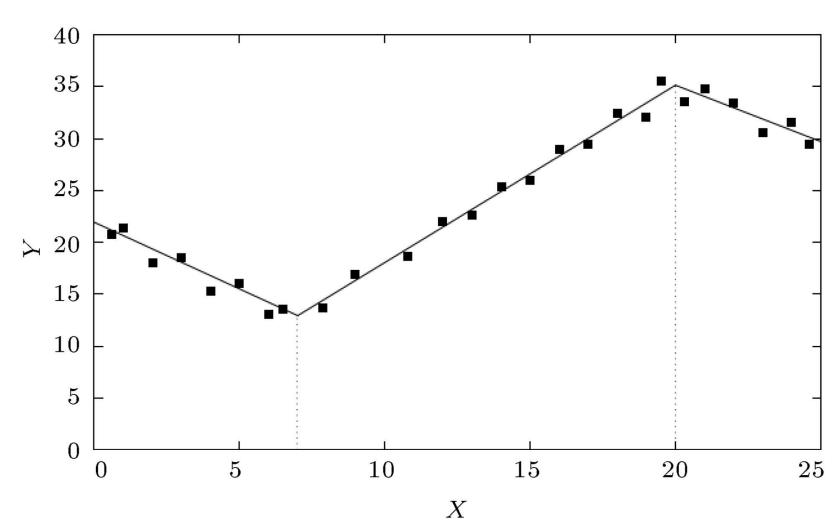

Figure 2. Example of fitting basis functions and knots.

parameter) and $\beta_{m}$ (weights) are determined from the regression data using the least square method. In this study, $X=\left[\frac{L}{d}, S_{u}, T_{k}, \theta, \frac{D}{L}\right]$ and $f(X)=Q$. The summation is done over $M$ terms in the model. Basis functions are piecewise linear or nonlinear functions that collectively approximate the true functions, representing the relationships between the dependent and independent variables. Piecewise linear functions can be written as $\max (0, x-t)$ point $t$ which is the position of a knot. $\max ($.$) is defined in symbols as follows:$

$$
\max (0, x-t)= \begin{cases}x-t, & \text { if } x \geq t \\ 0, & \text { otherwise }\end{cases}
$$

Figure 2 illustrates an example of fitting a predictive model to an arbitrary dataset using basis functions and knots. The fitted MARS regression model for the data in Figure 1 can be expressed as follows:

$$
\begin{aligned}
y= & -3.7980-4.0825 \times \mathrm{BF} 1+1.2860 \times \mathrm{BF} 2 \\
& +2.9950 \times \mathrm{BF} 3
\end{aligned}
$$

where $\mathrm{BF} 1=\max (0, x-20), \mathrm{BF} 2=\max (0,20-x)$, $\mathrm{BF} 3=\max (0, x-7)$, and $\max$ is defined as in $\max (a, b)$ which is equal to $a$ if $a>b$, else $b$. The knots are located at $x=7$ and 20. They mark the three intervals over which three different basis functions are defined.

MARS involves two steps of procedures: forward selection procedure and backward deletion procedure. These two steps are performed iteratively until a suitable model is obtained with minimum error. The detailed steps of the two procedures are as follows:

\section{- Step 1. Forward selection procedure:}

- At first, the model is built involving only the constant basis function (the intercept parameter);

- A search is performed for all possible knots;

- Between the possible knots, the regression data are approximated by basis functions with a minimum prediction error or maximized goodness of fit; 
- The last step is recursively applied until a model of predetermined maximum complexity is achieved (this step results in a purposefully overfitted model).

- Step 2. Backward deletion procedure: To eliminate the overfitting, a pruning operation is performed to eliminate all those basis functions that contribute the least to the overall goodness of fit. This process is continued recursively until the best possible submodel is found. The sub-models are compared using the method of Generalized Cross Validation (GCV). The GCV is a measure of goodness of fit that takes into account both residual error and complexity of the model and is calculated as follows:

$$
\mathrm{GCV}=\frac{\frac{1}{N} \sum_{i=1}^{N}\left[y_{i}-f\left(x_{i}\right)\right]^{2}}{\left[1-\frac{M+d \times(M-1) / 2}{N}\right]^{2}},
$$

where $M$ is the number of BFs, $d$ is the penalizing parameter, $N$ is the number of data sets, and $f\left(x_{i}\right)$ denotes the predicted values of the MARS model. The suitable range of $d$ is $2<d<3$ according to Hastie et al. [56]. An open source MARS code from Jekabsons is used to carry out the MARS analysis [57].

\section{Functional network}

Castillo et al. introduced Functional Network (FN) as a powerful alternative tool to deal with the limitations of standard ANN [46-48]. $\mathrm{FN}$ is termed as a novel generalization of ANN due to its ability to take into account both data as well as properties of functions being modelled (domain knowledge) to estimate the unknown neuron functions. Functional networks are based on functional equations and parametric modelling methods. According to Castillo et al., they require domain knowledge for deriving the functional equations and making assumptions about the form the unknown functions should take [46]. Though FN is similar to ANN, few differences in features make it more powerful and flexible compared to ANN [4648]. Figure 3 shows a typical neural network and its corresponding functional network. The main features that differentiate functional network from ANN are explained as follows:

- ANNs are black boxes and do not take into account the functional structure and domain knowledge. On the other hand, topology of FN derives information from both data and domain knowledge;

- In ANN, at each neuron, the activation functions are assumed to be fixed and known, and only the weights are learned. However, in FN, the neural functions are learned and weights are not required as they are already incorporated into the neural function;

- As shown in Figure 3(a), function $f$ of ANN is fixed; however, in Figure 3(b), functions $f_{1}, f_{2}, f_{3}$ of $\mathrm{FN}$ are different. Hence, in neural network, neural functions are of a single argument and univariate. However, in FN, as arbitrary neural functions are assumed, it has such flexibility to be multivariate and multiargumentative;

- As it can be seen from Figure 3(a), the ANN neuron outputs are different, while they can be concurrent or coincidental for functional network.

The knowledge of functional equations is used to work efficiently with functional networks, [47]. A functional equation is an equation in which the unknowns

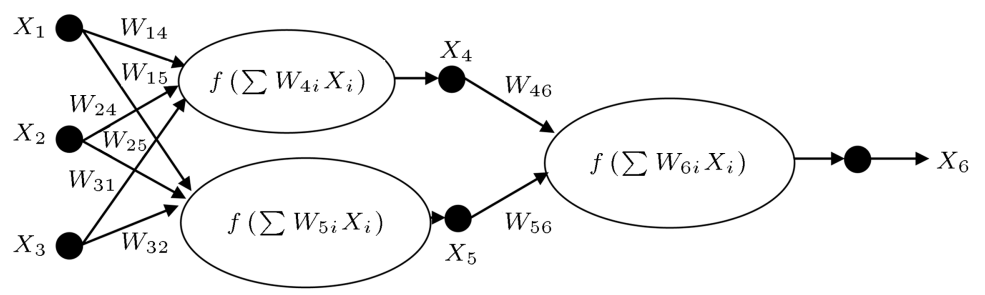

(a)

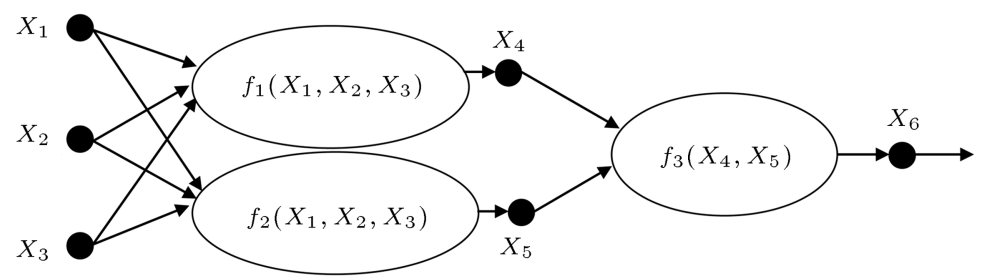

(b)

Figure 3. (a) A typical neural network, and (b) its corresponding functional network. 
are functions, excluding the differential and integral equations. The most typical example of functional equation is the Cauchy's functional equation which is as follows:

$$
f(x+y)=f(x)+f(y) .
$$

A functional network consists of the following components:

- One layer of input storing units containing the input data $\left(X_{1}, X_{2}\right.$, and $X_{3}$ in Figure $\left.3(\mathrm{~b})\right)$;

- One layer of output storing units containing the output data $\left(X_{6}\right.$ in Figure $\left.3(\mathrm{~b})\right)$;

- One or several layers of processing units which evaluate a set of input values, coming from the previous layer and delivering a set of output values to the next layer (cells containing functions $f_{1}, f_{2}$, and $f_{3}$ in Figure $\left.3(\mathrm{~b})\right)$;

- None, one, or several layers of intermediate storing units containing units which store intermediate information produced by neuron units $\left(X_{4}\right.$ and $X_{5}$ in Figure 3(b));

- A set of directed links which connects units in the input or intermediate layers to neuron units, and neuron units to intermediate or output units with arrows indicating direction of flow.

Castillo et al. presented various functional network models to solve different types of problems [47]:

(a) Uniqueness model;

(b) Generalized associativity model;

(c) Separable model;

(d) Generalized bisymmetry model;

(e) Serial functional model;

(f) Independent multiple output model;

(g) Dependent multiple output network;

(h) One-layer functional network;

out of which the general associative model is the most popular. The general working procedure of functional network model can be presented as follows:

- Selection of the initial topology: This selection is based on the type of problem;

- Simplification of the functional network: Simplification is done by solving corresponding systems of functional equations, reducing the network into equivalent functional network (network giving same output for any given input). This is also known as structural learning;

- Uniqueness of representation: This is done by assigning a unique property to a network to make it different from other equivalent networks;
- Parametric learning: Neural functions are estimated by considering linear combinations of appropriate functions based on the given data set;

- Model validation: The performances of the obtained approximating functions are measured by checking error criteria. The most commonly used error criterion is Euclidean norm error function and is given by:

$$
E=\sum_{i=1}^{n}\left[O_{i}-F\left(I_{i}\right)\right]^{2},
$$

for the dataset $D=\left(I_{i}, O_{i}\right), i=1,2, \cdots, n$. A crossvalidation is also performed with alternative set of data to detect overfitting.

The computational process of model fitting of a simple associative FN is illustrated using a simple functional network in Figure 4 with two inputs and one output. Herein, the inputs considered are $x_{1}$ and $x_{2}$, and the output is $x_{3}$. The network is learned using function $f(x)$ approximated as follows:

$$
f_{s}\left(x_{s}\right)=\sum_{i=1}^{m_{s}} a_{s i} \phi_{s i},
$$

where $\phi_{s i}$ is known as a shape function, which can be polynomial, exponential, trigonometric, logarithmic, or any other appropriate functions, $m_{s}$ is the degree of the function (in this example, it is considered as 1), and $s=1,2$ for two inputs.

According to the rule of associativity:

$$
\hat{f}\left(x_{3 j}\right)=f_{1}\left(x_{1 j}\right)+f_{2}\left(x_{2 j}\right), \quad j=1,2, \cdots, n .
$$

The error for the $j$ th data is as follows:

$$
e_{j}=\hat{f}\left(x_{3 j}\right)-f_{3}\left(x_{3 j}\right)=f_{1}\left(x_{1 j}\right)+f_{2}\left(x_{2 j}\right)-f_{3}\left(x_{3 j}\right) .
$$

This can be written in matrix form as follows:

$$
e_{j}=\left\langle 1, x_{1 j}, 1, x_{2 j},-1,-x_{3 j}\right\rangle\left\{\begin{array}{l}
a_{11} \\
a_{12} \\
a_{21} \\
a_{22} \\
a_{31} \\
a_{32}
\end{array}\right\},
$$

or:

$$
e_{j}=\left\langle b_{j}\right\rangle\{a\} .
$$

To estimate coefficient matrix $\{a\}$, the sum of squared

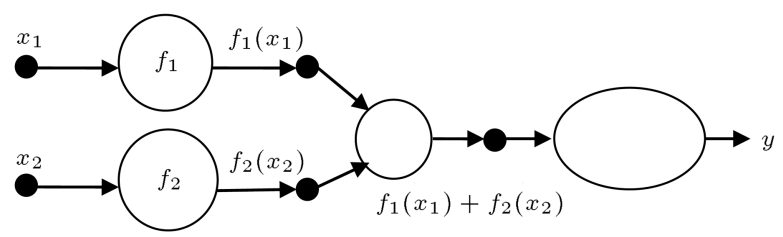

Figure 4. An example of a simple associative functional network. 
error, which is given in matrix form below, has to be minimized:

$$
\begin{aligned}
E & =\sum_{j=1}^{n} e_{j}^{2}=\sum_{j=1}^{n} e_{j}^{T} e_{j}=\langle a\rangle\left(\sum_{j=1}^{n}\left\{b_{j}\right\}\left\langle b_{j}\right\rangle\right)\{a\} \\
& =\langle a\rangle[A]\{a\},
\end{aligned}
$$

subjected to:

$$
f_{k}\left(x_{k 0}\right)=\sum_{i=1}^{m_{k}} a_{k i} \phi_{k i}\left(x_{k 0}\right),
$$

which can be expressed in the matrix form as follows:

$$
\langle a\rangle\left[\Phi_{0}\right]-\langle\alpha\rangle=0 .
$$

Using the Lagrange multiplier technique, an auxiliary function is defined as follows:

$$
Q_{\lambda}=\langle a\rangle[A]\{a\}+\langle a\rangle\left[\Phi_{0}\right]\{\lambda\}-\langle\lambda\rangle\{\alpha\} .
$$

The minimum of $Q_{\lambda}$ can be obtained from:

$$
\begin{aligned}
& \frac{\partial Q_{\lambda}}{\partial\{a\}}=2[A]\{a\}+\left[\Phi_{0}\right]\{\lambda\}=0, \\
& \frac{\partial Q_{\lambda}}{\partial \lambda}=\left[\Phi_{0}\right]^{T}\{a\}=\{\alpha\},
\end{aligned}
$$

which can be expressed as follows:

$$
\left[\begin{array}{cc}
2[A] & {\left[\Phi_{0}\right]} \\
{\left[\Phi_{0}\right]^{T}} & {[0]}
\end{array}\right]\left\{\begin{array}{l}
\{a\} \\
\{\lambda\}
\end{array}\right\}=\left\{\begin{array}{l}
\{0\} \\
\{\alpha\}
\end{array}\right\},
$$

or:

$$
[G]\{u\}=\{v\} .
$$

Through solving Eq. (18), coefficient matrix $\{u\}$ is obtained.

In this example, an arbitrary function, as shown in Eq. (19), involving two variables, is considered:

$$
y=\log \left(x_{1}+\exp \left(x_{2}\right)\right) \text {. }
$$

Then, a dataset is prepared as per Eq. (19); using the dataset and above-mentioned procedure, coefficient matrix $\{u\}$ was found which, after being substituted into Eq. (7), turns into the following form:

$$
\begin{aligned}
& f_{1}\left(x_{1}\right)=0.3820-0.1320 x_{1}, \\
& f_{2}\left(x_{2}\right)=0.5918-0.2018 x_{2}, \\
& f_{3}\left(x_{3}\right)=1.0034-0.6034 x_{3} .
\end{aligned}
$$

Substituting Eq. (20) into Eq. (8), the predicted output was obtained as follows:

$$
x_{3}=0.0491+0.2187 x_{1}+0.3344 x_{2} .
$$

Using a 30-point dataset, the correlation coefficient for the fitted model was found to be 0.99 .

In the present study, $\mathrm{FN}$ is implemented using Matlab [58].

\section{Experimental database and data preprocessing}

In the present study, the database available in the literature considered by Rahman et al. [26] develops FN and MARS models. The database assumed by Rahman et al. [26] contains information about five inputs: the aspect ratio of the caisson $(L / d)$, the undrained shear strength of the clay soil in which the caisson is installed $\left(S_{u}\right)$, the relative depth of the lug at which the caisson force is applied $(D / L)$, the angle that the chain force makes with the horizontal $(\theta)$, and the loading rate defined with respect to soil permeability $\left(T_{k}\right)$ as shown in Figure 1. The output is the uplift capacity of the caisson $(Q)$. The statistical descriptions of the training and testing dataset are shown in Table 1 . The database consists of 62 experimental test results from 12 independent studies. Out of the 62 data, 51 data are selected for training, and the remaining 11 are used for testing the GP, ANN, SVM, RVM, and FEM models as per Muduli et al. [37] and ELM model as per Muduli et al. [44]. For FN prediction model, Kenstone algorithm, based on Kennard and Stone [59], has been used to select training and testing data. A number of potential

Table 1. Statistical description of database used for development of different models.

\begin{tabular}{clcccc}
\hline $\begin{array}{c}\text { Model } \\
\text { variables }\end{array}$ & Type & $\begin{array}{c}\text { Maximum } \\
\text { value }\end{array}$ & $\begin{array}{c}\text { Minimum } \\
\text { value }\end{array}$ & Mean & $\begin{array}{c}\text { Standard } \\
\text { deviation }\end{array}$ \\
\hline$L / d$ & Input & 4 & 0.23 & 1.60 & 0.77 \\
$S_{u}(\mathrm{kPa})$ & Input & 38 & 1.8 & 11.75 & 10 \\
$T_{k}$ & Input & 0.04 & $1.00 \mathrm{E}-05$ & 0.0021 & 0.0086 \\
$\theta$ & Input & 90 & 0 & 72.52 & 32.54 \\
$D / L$ & Input & 0.69 & 0 & 0.058 & 0.17 \\
$Q(\mathrm{kPa})$ & Output & 387.2 & 10.1 & 90.064 & 80.67 \\
\hline
\end{tabular}


models have been generated using Kenstone algorithm among which the best model was found with 48 data as training data and the remaining 14 as testing data. The training and testing input and output data along with the functional network's predicted values are shown in Tables 2 and 3, respectively. The same training and testing data have been used for MARS model as well. In the case of MARS model, the normalization or scaling of datasets is not required; in the case of FN model, all the variables (input and output) are normalized in the range $[0,1]$ prior to being used in the model.

\section{Model development for uplift capacity of suction caisson}

With the use of trial and error method, it was found that piecewise-linear model gives better regression performance for MARS compared to piecewise-cubic model. Hence, the model is developed using piecewiselinear basis function. It was found that 18 is the optimum number of basis functions for which the best regression was obtained. The optimal MARS model is given by:

$$
Q=-85.63+\sum_{m=1}^{M} \beta_{m} \lambda_{m}(X) .
$$

The values of basis functions and corresponding coefficients are given in Table 4.

The functional network is developed with the five input variables, and computational process involves learning the functions $f_{i}, i=1,2, \cdots, 5$, as shown in Figure 5 from the data as follows:

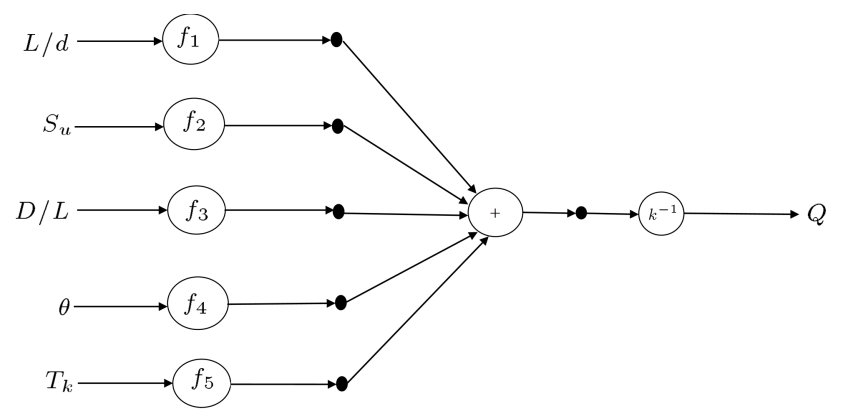

Figure 5. Associative functional network for the present problem.

$$
\begin{aligned}
k^{-1}(Q)= & f_{1}\left(\frac{L}{d}\right)+f_{2}\left(S_{u}\right)+f_{3}\left(\frac{D}{L}\right)+f_{4}(\theta) \\
& +f_{5}\left(T_{k}\right) .
\end{aligned}
$$

The error is defined as follows:

$$
\begin{aligned}
e_{j}= & \hat{f}_{1}\left(\frac{L}{d}\right)+\hat{f}_{2}\left(S_{u}\right)+\hat{f}_{3}\left(\frac{D}{L}\right)+\hat{f}_{4}(\theta) \\
& +\hat{f}_{5}\left(T_{k}\right)-k^{-1}(Q) .
\end{aligned}
$$

The functions involved in the above error function are estimated as follows:

$$
\begin{aligned}
& \hat{f}_{1}\left(\frac{L}{d}\right)=\sum_{j=1}^{m_{1}} a_{1 j} \Phi_{1 j}\left(\frac{L}{d}\right), \\
& \hat{f}_{2}\left(S_{u}\right)=\sum_{j=1}^{m_{2}} a_{2 j} \Phi_{2 j}\left(S_{u}\right), \\
& \hat{f}_{3}\left(\frac{D}{L}\right)=\sum_{j=1}^{m_{3}} a_{3 j} \Phi_{3 j}\left(\frac{D}{L}\right), \\
& \hat{f}_{4}(\theta)=\sum_{j=1}^{m_{4}} a_{4 j} \Phi_{4 j}(\theta) \\
& \hat{f}_{5}\left(T_{k}\right)=\sum_{j=1}^{m_{5}} a_{5 j} \Phi_{5 j}\left(T_{k}\right), \\
& k^{-1}(Q)=\sum_{j=1}^{m_{6}} a_{6 j} \Phi_{6 j}(Q) .
\end{aligned}
$$

The present problem is transformed into a series of equivalent associative functional networks as shown in Figure 6. First, a simple two-input functional network is analysed, and the output of which is further used as an input for the next two-input functional network, etc. The coefficients of the unknown functions are estimated using minimization algorithm.

The parameters of this functional network are:

(a) The shape functions, which are in the forms of polynomial, exponential, sine, cosine, tangent, logarithmic, etc.;

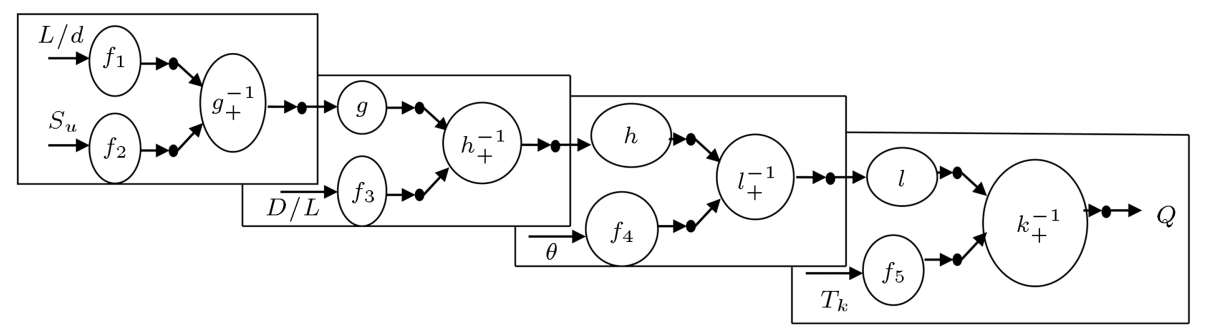

Figure 6. Associative functional network transformed into a series of equivalent functional networks. 
Table 2. Summary of training data for uplift capacity of suction pile using functional network.

\begin{tabular}{|c|c|c|c|c|c|c|}
\hline$L / d$ & $\begin{array}{c}S_{u} \\
(\mathrm{kPa})\end{array}$ & $T_{k}$ & $\theta$ & $D / L$ & $\begin{array}{c}Q_{\text {measured }} \\
(\mathrm{kPa})\end{array}$ & $\begin{array}{c}Q_{\text {predicted }} \\
(\mathbf{F N})(\mathbf{k P a})\end{array}$ \\
\hline 1.84 & 11.00 & 0.00001 & 90.00 & 0.00 & 88.20 & 96.50 \\
\hline 2.31 & 23.90 & 0.00001 & 15.00 & 0.69 & 387.20 & 387.25 \\
\hline 1.32 & 38.00 & 0.00001 & 0.00 & 0.00 & 134.90 & 134.91 \\
\hline 0.75 & 2.50 & 0.04000 & 90.00 & 0.00 & 10.10 & 7.11 \\
\hline 1.40 & 5.50 & 0.00001 & 10.00 & 0.56 & 71.80 & 71.81 \\
\hline 4.00 & 5.20 & 0.00001 & 75.00 & 0.47 & 48.10 & 48.11 \\
\hline 1.40 & 9.00 & 0.00001 & 0.00 & 0.00 & 37.00 & 37.00 \\
\hline 4.00 & 5.20 & 0.00001 & 90.00 & 0.00 & 48.80 & 48.80 \\
\hline 2.00 & 25.00 & 0.00001 & 90.00 & 0.00 & 244.10 & 244.82 \\
\hline 0.23 & 24.00 & 0.00001 & 0.00 & 0.00 & 72.00 & 72.00 \\
\hline 0.43 & 4.20 & 0.00001 & 80.00 & 0.00 & 48.70 & 48.70 \\
\hline 0.70 & 13.70 & 0.00001 & 90.00 & 0.00 & 135.00 & 135.00 \\
\hline 1.50 & 1.80 & 0.00010 & 90.00 & 0.00 & 12.90 & 12.92 \\
\hline 0.23 & 31.00 & 0.00001 & 0.00 & 0.05 & 128.30 & 128.31 \\
\hline 1.84 & 15.80 & 0.00001 & 90.00 & 0.00 & 160.50 & 161.51 \\
\hline 1.50 & 6.00 & 0.04000 & 90.00 & 0.00 & 23.00 & 22.92 \\
\hline 0.75 & 2.50 & 0.00400 & 90.00 & 0.00 & 13.20 & 10.86 \\
\hline 2.00 & 5.80 & 0.00010 & 90.00 & 0.00 & 46.40 & 41.15 \\
\hline 0.68 & 24.00 & 0.00001 & 0.00 & 0.00 & 21.30 & 21.30 \\
\hline 1.40 & 9.00 & 0.00001 & 0.00 & 0.50 & 70.50 & 70.51 \\
\hline 1.00 & 5.80 & 0.00010 & 90.00 & 0.00 & 35.60 & 33.66 \\
\hline 1.50 & 6.00 & 0.00400 & 90.00 & 0.00 & 26.60 & 26.67 \\
\hline 2.00 & 20.50 & 0.00001 & 90.00 & 0.00 & 209.40 & 207.56 \\
\hline 1.32 & 14.30 & 0.00001 & 90.00 & 0.00 & 144.60 & 160.45 \\
\hline 0.40 & 6.80 & 0.00001 & 90.00 & 0.00 & 75.00 & 75.00 \\
\hline 1.32 & 38.00 & 0.00001 & 0.00 & 0.10 & 149.00 & 149.01 \\
\hline 2.00 & 1.80 & 0.00010 & 90.00 & 0.00 & 15.60 & 18.19 \\
\hline 1.00 & 1.80 & 0.00010 & 90.00 & 0.00 & 11.10 & 10.69 \\
\hline 0.75 & 6.00 & 0.00400 & 90.00 & 0.00 & 26.00 & 28.27 \\
\hline 1.50 & 5.80 & 0.00010 & 90.00 & 0.00 & 38.10 & 35.89 \\
\hline 0.75 & 6.00 & 0.04000 & 90.00 & 0.00 & 21.50 & 24.52 \\
\hline 2.00 & 8.30 & 0.00001 & 90.00 & 0.00 & 71.70 & 78.64 \\
\hline 2.31 & 21.60 & 0.00001 & 11.00 & 0.68 & 370.40 & 370.42 \\
\hline 1.32 & 14.30 & 0.00001 & 90.00 & 0.00 & 176.30 & 160.45 \\
\hline 0.75 & 2.50 & 0.00040 & 90.00 & 0.00 & 15.70 & 14.64 \\
\hline 2.00 & 3.60 & 0.00010 & 90.00 & 0.00 & 33.60 & 36.26 \\
\hline 0.75 & 6.00 & 0.00040 & 90.00 & 0.00 & 31.00 & 32.05 \\
\hline 1.50 & 3.60 & 0.00010 & 90.00 & 0.00 & 28.80 & 30.99 \\
\hline 1.00 & 3.60 & 0.00010 & 90.00 & 0.00 & 26.40 & 28.76 \\
\hline 2.00 & 22.50 & 0.00001 & 90.00 & 0.00 & 214.90 & 211.33 \\
\hline 2.00 & 6.00 & 0.00001 & 90.00 & 0.00 & 66.30 & 66.31 \\
\hline 2.00 & 9.00 & 0.00001 & 90.00 & 0.00 & 90.10 & 83.20 \\
\hline 1.84 & 11.00 & 0.00001 & 90.00 & 0.00 & 105.80 & 96.50 \\
\hline 2.00 & 7.00 & 0.00001 & 90.00 & 0.00 & 80.20 & 70.21 \\
\hline 2.00 & 10.50 & 0.00001 & 90.00 & 0.00 & 90.40 & 90.14 \\
\hline 2.00 & 24.00 & 0.00001 & 90.00 & 0.00 & 245.30 & 243.09 \\
\hline 2.00 & 22.50 & 0.00001 & 90.00 & 0.00 & 204.90 & 211.33 \\
\hline 2.00 & 7.80 & 0.00001 & 90.00 & 0.00 & 64.50 & 75.20 \\
\hline
\end{tabular}


Table 3. Summary of testing data for uplift capacity of suction pile using functional network.

\begin{tabular}{ccccccc}
\hline $\boldsymbol{L} / \boldsymbol{d}$ & $\begin{array}{c}\boldsymbol{S}_{\boldsymbol{u}} \\
(\mathbf{k P a})\end{array}$ & $\boldsymbol{T}_{\boldsymbol{k}}$ & $\boldsymbol{\theta}$ & $\boldsymbol{D} / \boldsymbol{L}$ & $\begin{array}{c}\boldsymbol{Q}_{\text {measured }} \\
(\mathbf{k P a})\end{array}$ & $\begin{array}{c}\boldsymbol{Q}_{\text {predicted }} \\
(\mathbf{F N})(\mathbf{k P a})\end{array}$ \\
\hline 1.00 & 2.40 & 0.00010 & 90.00 & 0.00 & 15.20 & 15.38 \\
1.32 & 38.00 & 0.00001 & 0.00 & 0.10 & 145.50 & 149.01 \\
1.32 & 14.30 & 0.00001 & 90.00 & 0.00 & 149.90 & 160.45 \\
1.50 & 6.00 & 0.00040 & 90.00 & 0.00 & 32.20 & 30.46 \\
1.50 & 2.40 & 0.00010 & 90.00 & 0.00 & 18.70 & 17.61 \\
1.84 & 11.00 & 0.00001 & 90.00 & 0.00 & 86.40 & 96.50 \\
1.84 & 11.00 & 0.00001 & 90.00 & 0.00 & 92.60 & 96.50 \\
2.00 & 7.50 & 0.00001 & 90.00 & 0.00 & 70.50 & 73.20 \\
2.00 & 8.50 & 0.00001 & 90.00 & 0.00 & 75.30 & 80.00 \\
2.00 & 6.00 & 0.00001 & 90.00 & 0.00 & 62.70 & 66.31 \\
4.00 & 5.20 & 0.00001 & 75.00 & 0.47 & 54.90 & 48.11 \\
1.32 & 38.00 & 0.00001 & 0.00 & 0.00 & 133.10 & 134.91 \\
1.84 & 15.80 & 0.00001 & 90.00 & 0.00 & 154.30 & 161.51 \\
2.00 & 2.40 & 0.00010 & 90.00 & 0.00 & 21.90 & 22.88 \\
\hline
\end{tabular}

Table 4. Basis Functions and their corresponding coefficients.

\begin{tabular}{clc}
\hline $\begin{array}{c}\text { Basis } \\
\text { function }\end{array}$ & \multicolumn{1}{c}{ Equation } & Coefficient \\
\hline $\mathrm{BF} 1$ & $\max \left(0, S_{u}-22.5\right)$ & 6.8063 \\
$\mathrm{BF} 2$ & $\mathrm{BF} 1^{*} \max (0, L / d-2)$ & -190.82 \\
$\mathrm{BF} 3$ & $\mathrm{BF} 1^{*} \max (0,2-L / d)$ & 19.078 \\
$\mathrm{BF} 4$ & $\max (0, D / L+0)$ & -11529 \\
$\mathrm{BF} 5$ & $\max (0, \theta-80)$ & 23.45 \\
$\mathrm{BF} 6$ & $\max (0,80-\theta)$ & 1.039 \\
$\mathrm{BF} 7$ & $\mathrm{BF} 6^{*} \max (0, L / d-1.4)$ & 132.08 \\
$\mathrm{BF} 8$ & $\mathrm{BF} 6^{*} \max (0,1.4-L / d)$ & 1.0506 \\
$\mathrm{BF} 9$ & $\mathrm{BF} 5^{*} \max \left(0, S_{u}-14.3\right)$ & 1.3743 \\
$\mathrm{BF} 10$ & $\mathrm{BF} 5^{*} \max \left(0,14.3-S_{u}\right)$ & -2.5355 \\
$\mathrm{BF} 11$ & $\mathrm{BF} 4^{*} \max (0, \theta-11)$ & -55.235 \\
$\mathrm{BF} 12$ & $\mathrm{BF} 4^{*} \max (0,11-\theta)$ & 255.14 \\
$\mathrm{BF} 13$ & $\mathrm{BF} 5^{*} \max \left(0, T_{k}-0.0001\right)$ & -33.11 \\
$\mathrm{BF} 14$ & $\mathrm{BF} 5^{*} \max \left(0,0.0001-T_{k}\right)$ & 31198 \\
$\mathrm{BF} 15$ & $\max \left(0, S_{u}-11\right)$ & -6.5147 \\
$\mathrm{BF} 16$ & $\max \left(0,11-S_{u}\right)$ & 19.754 \\
$\mathrm{BF} 17$ & $\mathrm{BF} 4^{*} \max \left(0, S_{u}-21.6\right)$ & 540.48 \\
$\mathrm{BF} 18$ & $\mathrm{BF} 4^{*} \max \left(0,21.6-S_{u}\right)$ & 697.61 \\
\hline & & \\
\hline
\end{tabular}

(b) Degree of the shape function;

(c) The unknown neural function coefficients, which are determined from the learning data.

As the degree of the shape function increases, the accuracy as well as complexity of the prediction model also increase.

In the present study, a number of potential FN models are developed among which the exponential function with a degree of 10 provides the best regression model, and the equation is presented as follows:

$$
y=-791.227+\sum_{i=1}^{n} \sum_{j=1}^{m} a_{i j} e^{x_{i}^{j}}
$$

where $n$ is the number of variables (inputs), which is 5 and $m$ is the degree of variable (degree of the function), which is 10 for the present problem. The trial and error method was employed to select the best shape function and degree that presents the highest regression model.

\section{Performance analysis and model validation}

The fitness of each model is determined in terms of five parameters, namely correlation coefficient $(R)$, NashSutcliffe coefficient of efficiency $(E)$ [25], Average Absolute Error (AAE), Maximum Absolute Error (MAE), and RMSE as defined in Eq. (32):

$$
E=\frac{E_{1}-E_{2}}{E_{1}}
$$

where:

$$
E_{1}=\sum_{t=1}^{N}\left(Q_{m}-\overline{Q_{m}}\right)^{2},
$$

and:

$$
\begin{aligned}
& E_{2}=\sum_{t=1}^{N}\left(Q_{p}-Q_{m}\right)^{2}, \\
& \mathrm{AAE}=\frac{1}{n} \sum_{i=1}^{n}\left|Q_{m}-Q_{p}\right|,
\end{aligned}
$$




$$
\begin{aligned}
& \text { MAE }=\max \left|Q_{m}-Q_{p}\right|, \\
& \mathrm{RMSE}=\sqrt{\frac{\sum_{i=1}^{n}\left(Q_{m}-Q_{p}\right)^{2}}{n}},
\end{aligned}
$$

where $n$ is the number data points, and $Q_{m}$ and $Q_{p}$ are the measured and predicted values of uplift capacity, respectively. The above statistical measures for testing data for all the methods, namely FN, GP, ANN, FEM, MARS, SVM, and RVM, are presented in Table 5. It indicates the robustness of the FN and MARS models, as they outperform all the other models in terms of most of the statistical parameters under consideration.

Das and Sivakugan [60] found that only $R$ value is not sufficient to show good prediction. Thus, the model's external validation was performed on the testing dataset as per recommendations of Golbraikh and Tropsha [61] and Roy and Roy [62]. Table 6 shows the validation criteria and the corresponding values obtained. It is seen from Table 6 that both of the models satisfy the validation criteria; hence, the validity and prediction capability of the models are verified.

\section{Results and discussions}

$R$ and $E$ values for the developed FN model for training dataset are found to be 0.998 and 0.997 , respectively, and for the testing dataset, the corresponding values are 0.997 and 0.988 , respectively. Thus, the developed FN model shows good generalization in terms of close values of $R$ and $E$ for both training and testing datasets.

Similarly, for MARS model, $R$ and $E$ values for training dataset are found to be 0.997 and 0.994 , respectively, and for testing dataset, the corresponding values are 0.994 and 0.989 , respectively. Thus, the developed MARS model also shows good generalization in terms of close values of $R$ and $E$ for both training and testing datasets.

Since the efficiency comparison of a model is an important task to perform with respect to the testing data rather than training data, Das and Basudhar [25], in this study, performed the comparison of the methods with respect to the testing data only. Figure 7 shows the performances of the predicted and observed values of uplift capacity of suction caisson for FN and other models (FEM, ANN, SVM, RVM, GP, and ELM)

Table 5. Comparison of statistical performances of different models.

\begin{tabular}{lccccc}
\hline \multirow{2}{*}{ Models } & \multicolumn{5}{c}{ Statistical performances } \\
\cline { 2 - 6 } & $\boldsymbol{R}$ & $\boldsymbol{E}$ & AAE & MAE & RMSE \\
\hline FN & 0.997 & 0.988 & 4.142 & 10.614 & 5.292 \\
MARS & 0.994 & 0.989 & 4.300 & 11.996 & 5.145 \\
GP [44] & 0.997 & 0.988 & 8.065 & 27.055 & 11.155 \\
FEM [26] & 0.995 & 0.986 & 8.490 & 21.100 & 11.876 \\
ANN [26] & 0.991 & 0.975 & 12.204 & 32.820 & 16.031 \\
SVM [44] & 0.989 & 0.955 & 15.640 & 42.020 & 21.310 \\
RVM [44] & 0.992 & 0.964 & 14.960 & 35.980 & 19.040 \\
ELM [44] & 0.998 & 0.995 & 5.674 & 14.017 & 6.777 \\
GMDH-HS [45] & 0.998 & 0.996 & - & - & 6.740 \\
\hline
\end{tabular}

\begin{tabular}{|c|c|c|c|c|}
\hline S1. no. & Parameters & Criteria & FN & MARS \\
\hline 1 & $R=\frac{\sum\left(y_{i}-\bar{y}\right)\left(\tilde{y}_{i}-\overline{\tilde{y}}\right)}{\sqrt{\sum\left(y_{i}-\bar{y}\right)^{2} \sum\left(\tilde{y}_{i}-\bar{y}\right)^{2}}}$ & $0.8<R$ & 0.997 & 0.997 \\
\hline 2 & $k=\frac{\sum y_{i} \tilde{y}_{i}}{\sum \tilde{y}_{i}^{2}}$ & $0.85<k<1.15$ & 1.042 & 1.036 \\
\hline 3 & $k^{\prime}=\frac{\sum y_{i} \tilde{y}_{i}}{\sum y_{i}^{2}}$ & $0.85<k^{\prime}<1.15$ & 0.959 & 0.963 \\
\hline 4 & $m=\frac{R^{2}-R_{0}^{2}}{R^{2}}, R_{0}^{2}=1-\frac{\sum\left(\tilde{y}_{i}-y_{i}^{r_{0}}\right)^{2}}{\sum\left(\tilde{y}_{i}-\tilde{y}\right)^{2}}, y_{i}^{r_{0}}=k \tilde{y}_{i}$ & $|m|<0.1$ & 0.0065 & 0.0037 \\
\hline 5 & $n=\frac{R^{2}-R_{0}^{\prime 2}}{R^{2}}, R_{0}^{\prime 2}=1-\frac{\sum\left(y_{i}-\tilde{y}_{i}^{r_{0}}\right)^{2}}{\sum\left(y_{i}-\bar{y}\right)^{2}}, \tilde{y}_{i}^{r_{0}}=k^{\prime} y_{i}$ & $|n|<0.1$ & 0.0067 & 0.0043 \\
\hline 6 & $R_{m}=R^{2} \times\left(1-\sqrt{\left|R^{2}-R_{0}^{2}\right|}\right)$ & $0.5<R_{m}$ & 0.914 & 0.933 \\
\hline
\end{tabular}

Table 6. Statistical parameters of the models for external validation on testing data set as per Golbraikh and Tropsha [61]. 


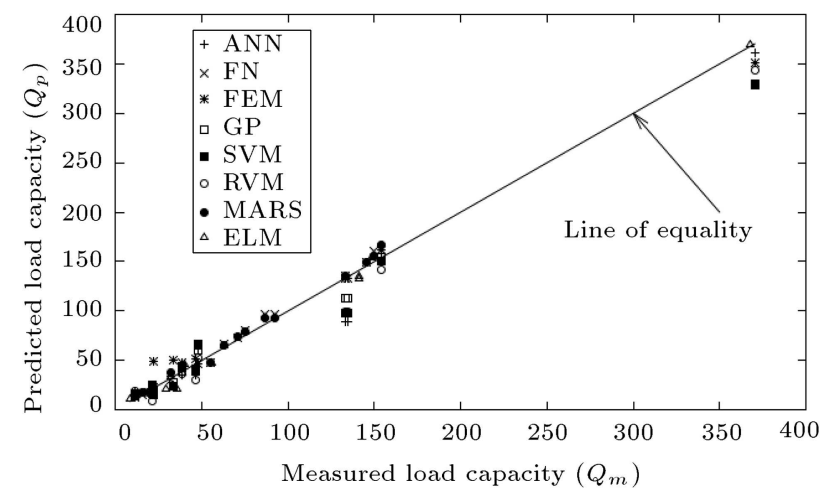

Figure 7. Comparisons of the predicted and measured uplift capacities of suction caisson by different models for testing data.

available in literature for the testing data. It is observed that there is less scatter in data for $\mathrm{FN}$ and MARS models as compared to other models.

Abu-Farsakh and Titi [54] as well as Das and Basudhar [29] emphasized that other statistical criteria should be used while describing prediction of ultimate load capacity of driven pile based on Cone Penetration Test (CPT) data and lateral load capacity of piles, respectively. The mean and standard deviation of $Q_{p} / Q_{m}$ are important indicators of the accuracy and precision of the prediction method. Under ideal conditions, an accurate and precise method should give the mean value as 1.0 and the standard deviation as 0.0. In reality, any method which gives a mean value close to 1.0 and standard deviation close to 0.0 is capable of good estimation. Value of $\mu$ greater than 1.0 indicates overprediction and less than 1.0 indicates underprediction. The cumulative probability of $Q_{p} / Q_{m}$, according to Abu-Farsakh and Titi [54] as well as Das and Basudhar [29], should be also considered for the evaluation of different models.

Ratio $Q_{p} / Q_{m}$ is arranged in ascending order, and

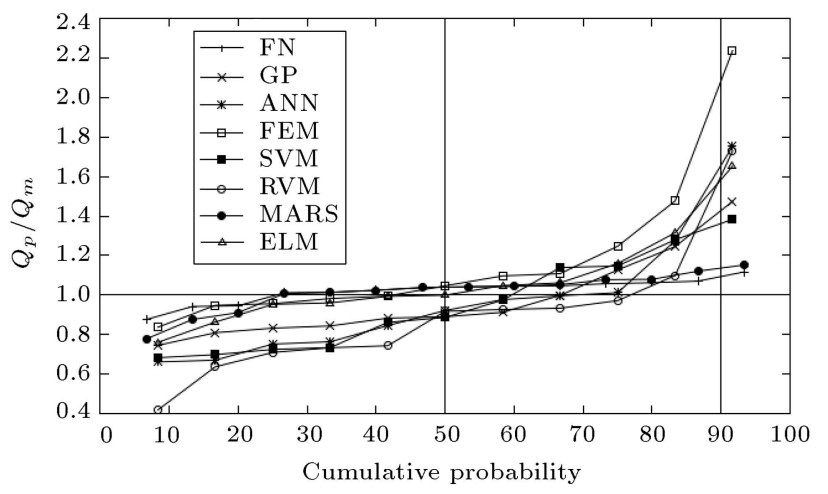

Figure 8. Cumulative probability plots of $Q_{p} / Q_{m}$ for different models for testing data.

the cumulative probability is calculated through the following equation:

$$
P=\frac{i}{n+1}
$$

where $i$ is the order number which is assigned to $Q_{p} / Q_{m}$ value, and $n$ is the number of data points.

The "best" model corresponds to the model with $50 \%$ cumulative probability $\left(P_{50}\right)$ value close to unity. If the computed value of $P_{50}$ is less than unity, underprediction is implied; values greater than unity imply overprediction. For a model, 90\% cumulative probability $\left(P_{90}\right)$ reflects a variation in the ratio of $Q_{p} / Q_{m}$. The model with $P_{90}$ for $Q_{p} / Q_{m}$ close to 1.0 is a better model.

Figure 8 shows the cumulative probability plots of $Q_{p} / Q_{m}$ for different methods. It can be seen from Figure 8 and Table 7 that FN $\left(P_{50}=1.040\right)$, MARS $\left(P_{50}=1.040\right), \operatorname{ELM}\left(P_{50}=1.001\right), \mathrm{GP}\left(P_{50}=0.950\right)$, FEM $\left(P_{50}=1.050\right)$, and ANN $\left(P_{50}=0.960\right)$ models are equally good as $P_{50}$ values are very close to 1 .

The corresponding SVM and RVM values are found to be 0.890 and 0.920 , respectively, showing

Table 7. Evaluation of performances of different prediction models considered in this study.

\begin{tabular}{|c|c|c|c|c|c|c|c|c|c|c|c|c|c|c|}
\hline \multirow[t]{2}{*}{ Models } & \multicolumn{3}{|c|}{$\begin{array}{c}\text { Best fit } \\
\text { calculations }\end{array}$} & \multicolumn{3}{|c|}{$\begin{array}{c}\text { Arithmetic } \\
\text { calculations } \\
\text { of } Q_{p} / Q_{m}\end{array}$} & \multicolumn{3}{|c|}{$\begin{array}{l}\text { Cumulative } \\
\text { probability }\end{array}$} & \multicolumn{3}{|c|}{ $\pm 20 \%$ accuracy } & \multicolumn{2}{|c|}{$\begin{array}{c}\text { Overall } \\
\text { rank }\end{array}$} \\
\hline & $\boldsymbol{R}$ & $E$ & $R 1$ & Mean & $\sigma$ & $R 2$ & $\begin{array}{c}Q_{p} / Q_{m} \\
\text { at } P_{50}\end{array}$ & $\begin{array}{c}Q_{p} / Q_{m} \\
\text { at } P_{90}\end{array}$ & $R 3$ & $\begin{array}{c}\text { Log } \\
\text { normal }\end{array}$ & Histogram & $R 4$ & $R I$ & $\begin{array}{c}\text { Final } \\
\text { rank }\end{array}$ \\
\hline $\mathrm{FN}$ & 0.997 & 0.988 & 3 & 1.021 & 0.062 & 1 & 1.040 & 1.100 & 1 & 100 & 100 & 1 & 6 & 1 \\
\hline MARS & 0.994 & 0.989 & 4 & 1.015 & 0.099 & 2 & 1.040 & 1.135 & 2 & 97 & 93 & 2 & 10 & 2 \\
\hline FEM [26] & 0.995 & 0.986 & 4 & 1.175 & 0.391 & 8 & 1.050 & 2.100 & 9 & 45 & 72 & 6 & 27 & 6 \\
\hline ANN [26] & 0.991 & 0.975 & 5 & 1.065 & 0.454 & 9 & 0.960 & 2.100 & 8 & 48 & 46 & 9 & 31 & 8 \\
\hline SVM [37] & 0.989 & 0.955 & 7 & 0.956 & 0.248 & 6 & 0.890 & 1.380 & 7 & 53 & 46 & 8 & 28 & 7 \\
\hline RVM [37] & 0.992 & 0.964 & 6 & 0.893 & 0.335 & 7 & 0.920 & 1.600 & 6 & 38 & 72 & 7 & 26 & 5 \\
\hline GP [37] & 0.997 & 0.988 & 3 & 1.026 & 0.191 & 3 & 0.950 & 1.380 & 5 & 72 & 82 & 4 & 16 & 4 \\
\hline ELM [44] & 0.998 & 0.995 & 2 & 1.069 & 0.241 & 5 & 1.001 & 1.220 & 3 & 64 & 72 & 5 & 15 & 3 \\
\hline GMDH-HS [45] & 0.997 & 0.996 & 1 & 1.085 & 0.165 & 4 & 1.028 & 1.331 & 4 & 91 & 87 & 3 & 12 & 3 \\
\hline
\end{tabular}


underprediction. However, based on $P_{90}$ value, FN (1.10), MARS (1.135) and ELM (1.220) models are found to be better than SVM (1.380), GP (1.380), RVM (1.600), ANN (2.100), and FEM (2.100) models. While taking both $P_{50}$ and $P_{90}$ values into account, FN model is found to be better than other models. The lognormal distributions of $Q_{p} / Q_{m}$ for different models of the testing data are shown in Figure 9. Based on the plots, it can be seen that FN model is better than the MARS, ELM, GP, FEM, ANN, SVM, and RVM models within $\pm 20 \%$ accuracy level, as the shaded area under the lognormal distribution plot of $Q_{p} / Q_{m}$ for FN is larger than that of the other models.

Rankings are assigned to different models, with ranking criteria $R 1$ obtained from the best fit calculations $(R, E), R 2$ from arithmetic calculations of $Q_{p} / Q_{m}(\mu, \sigma), R 3$ from cumulative probability of $Q_{p} / Q_{m}\left(P_{50}, P_{90}\right)$, and $R 4$ from prediction of $Q_{p}$ within $20 \%$ accuracy level. The overall performances of the various models are evaluated using a Rank Index $(R I)$ provided by Abu-Farsakh and Titi [54], where $R I$ is the sum of ranks obtained from the above four criteria $(R I=R 1+R 2+R 3+R 4)$. A lower value of $R I$ indicates a better performance of a particular model, which is presented in Table 7 in the present study. Based on Table 7, it can be seen that the developed FN model is the "best" model followed by MARS, GMDHHS, ELM, GP, FEM, RVM, SVM, and ANN. However, as the AI techniques are problem-dependent, such a study should be done for other complex geotechnical engineering problems to identify the efficacy of the FN model.

An important shortcoming of FN is the limitation to make a trade-off between the accuracy and complexity as the complexity of the model equation increases upon an increase in accuracy rate. A trial and error process has to be employed to select the type of network and that of neural functions to be used. The main disadvantage of MARS model is the computational complexity and speed.

With regard to the computational efficiency, it

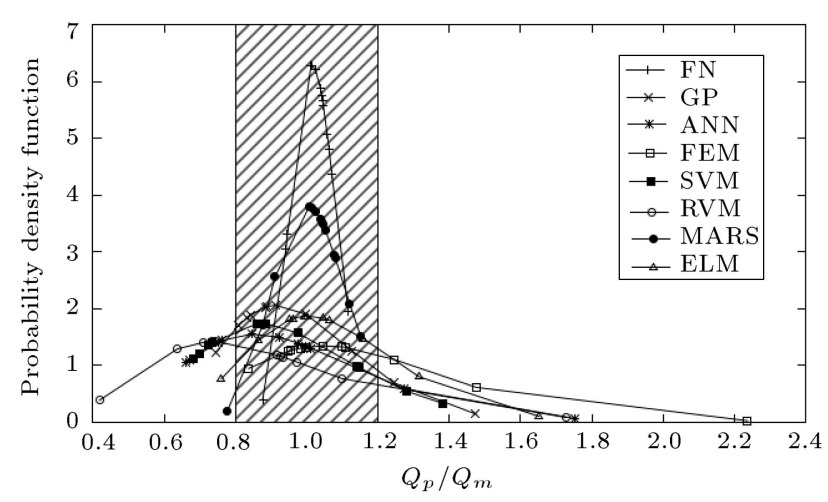

Figure 9. $\log$ normal distribution of $Q_{p} / Q_{m}$ for different models for testing data. was found that both FN and MARS models are equally efficient in terms of computation. The execution times for both of the models are less than $1 \mathrm{sec}$. The models were executed on Intel Core i5 @3.2GHz processor with 4 GB RAM. The computational efficiencies of the other methods were not available in the literature for comparison $[37,44]$.

\section{Conclusions}

In this paper, two most recently used AI techniques, i.e. functional network and MARS, have been used for the prediction of uplift capacity of suction caisson problem. Various AI methods have been used previously to solve the present problem with some level of accuracy. Based on the comparison, with the predicted results of ELM, GP, SVM, RVM, and ANN and the most recent GMDH-HS models available in literature, it was observed that the presented methods, FN and MARS, showed higher accuracy level. This paper also shows the application of FN to potential geotechnical engineering problems and opens doors for many similar problems to be analysed using FN.

Based on the above results and discussions, the following conclusions can be drawn.

For FN model, $R$ and $E$ values for training dataset are found to be 0.998 and 0.997 , respectively; for testing dataset, the corresponding values are 0.997 and 0.988 , respectively, showing good generalization. Similarly, for MARS model, $R$ and $E$ values for training dataset are found to be 0.997 and 0.994 , respectively, and for testing dataset, the corresponding values are 0.994 and 0.989 . The validities of the models are tested using several external validation criteria, which show that the models are strongly valid and capable of accurate prediction. Based on the four ranking criteria [best fit calculations $(R, E)$, arithmetic calculations of $Q_{p} / Q_{m}(\mu, \sigma)$, cumulative probability of $Q_{p} / Q_{m}\left(P_{50}, P_{90}\right)$, and prediction of $Q_{p}$ within $20 \%$ accuracy level], the developed FN and MARS models are found to be more efficient compared to other AI models, followed by ELM, GP, RVM, FEM, SVM, and ANN. The study also shows that FN model is better than MARS model in three out of the above four ranking criteria. Hence, the FN model is more efficient than other AI models for the prediction of uplift capacity of suction caisson in clay and needs to be applied to more complex geotechnical problems to determine its accuracy and effectiveness over other AI techniques.

\section{References}

1. Senepere, D. and Auvergne, G.A. "Suction anchor piles-a proven alternative to driving and drilling", Offshore Technology Conference, Houston, Texas, Houston, Texas, Paper No. 4206 (1982). 
2. Albert, L.F., Holtz, R.D., and Magris, E. "The superpile system: A feasible alternate foundation for TLP in deep water", In Proceedings of the 19th Annual Offshore Technology Conference, Houston, Texas, OTC 5392, pp. 307-314 (1987).

3. Clukey, E.C., Morrison, M.J., Gariner, J., and Corte, J.F. "The response of suction caisson in normally consolidated clays to cyclic TLP loading conditions", Proceedings of the 27th Annual Offshore Technology Conference, Houston, Texas, pp. 909-918 (1995).

4. Cao, J., Phillips, R., and Popescu, R. "Physical and numerical modelling on suction caissons in clay", Proceedings of the 18th Canadian Congress of Applied Mechanics, Memorial University of Newfoundland, St. John's, Canada, pp. 217-218 (2001).

5. Cao, J., Phillips, R., Audibert, J.M.E., and AlKhafazi, Z. "Numerical analysis of the behaviour of suction caissons in clay", Proceedings of the 12th International Offshore and Polar Engineering Conference, Kitakyushu, Japan, pp. 795-799 (2002a).

6. Cao, J., Phillips, R., Popescu, R., Al-Khafaji, Z., and Audibert, J.M.E. "Penetration resistance of suction caissons in clay", Proceedings of the 12th International Offshore and Polar Engineering Conference, Kitakyushu, Japan, pp. 800-806 (2002b).

7. El-Gharbawy, S.L. and Olson, R.E. "Modeling of suction caisson foundations", Proceedings of the 10th International Offshore and Polar Engineering Conference, Seattle, Washington, USA (2000).

8. Whittle, A.J. and Kavvadas, M.J. "Formulation of MIT-E3 constitutive model for overconsolidated clays", Journal of Geotechnical Engineering, 120(1), pp. 173-198 (1994).

9. Zdravkovic, L., Potts, D.M., and Jardine, R.J. "A parametric study of the pull-out capacity of bucket foundations in soft clay", Geotechnique, 51(1), pp. 5567 (2001).

10. Goodman, L.J., Lee, C.N., and Walker, F.J. "The feasibility of vacuum anchorage in soil", Geotechnique, 1(4), pp. 356-359 (1961).

11. Larsen, P. "Suction anchors as an anchoring system for floating offshore constructions", Proc. 21st Annual Offshore Technology Conference, Houston, TX, pp. 535-540 (1989).

12. Steensen-Bach, J.O. "Recent model tests with suction piles in clay and sand", Proceedings of the 24th Annual Offshore Technology Conference, Houston, TX, 2, pp. 323-330 (1992).

13. Datta, M. and Kumar, P. "Suction beneath cylindrical anchors in soft clay", Proceedings of the Sixth International Offshore and Polar Engineering Conference, Los Angeles, California, pp. 544-548 (1996).

14. Singh, B., Datta, M., and Gulhati, S.K. "Pullout behavior of superpile anchors in soft clay under static loading", Marine Georesources and Geotechnology, 14, pp. 217-236 (1996).
15. Rao, S.N., Ravi, R., and Ganapathy, C. "Behavior of suction anchors in marine clays under TLP loading", Proceedings of the 16th International Conference on Offshore Mechanics and Arctic Engineering, Yokohama, Japan, 1, pp. 151-155 (1997a).

16. Rao, S.N., Ravi, R., and Ganapathy, C. "Pullout behavior of model suction anchors in soft marine clays", Proceedings of the Seventh International Offshore and Polar Engineering Conference, Honolulu, HI, pp. 740744 (1997b).

17. Kumar, N.D. and Rao, S.N. "Lateral load of cylindrical caisson in shore protection: a laboratory study", Coast. Eng. J., 53(4), pp. 365-395 (2011).

18. Clukey, E.C. and Morrison, M.J. "A centrifuge and analytical study to evaluate suction caissons for TLP applications in the Gulf of Mexico", Design and Performance of Deep Foundations: Piles and Piers in Soil and Soft Rock, P.P. Nelson, T.D. Smith and E.C. Clukey, Eds., ASCE Geotechnical Special Publication, 38, pp. 141-156 (1993).

19. Chen, W. and Randolph, M.F. "Uplift capacity of suction caissons under sustained and cyclic loading in soft clay", Journal of Geotechnical and Geoenvironmental Engineering, 133(11), pp. 1352-1363 (2007).

20. Hogervorst, J.R. "Field trails with large diameter suction piles", Proceedings of the 12th annual Offshore Technology Conference, Houston, Texas, pp. 217-224 (1980).

21. Tjelta, T.I., Guttormsen, T.R., and Hermstad, J. "Large-scale penetration test at a deepwater site", Proceedings of the 18th Annual Offshore Technology Conference, Houston, TX, pp. 201-212 (1986).

22. Dyvik, R., Anderson, K.H., Hansen, S.B., and Christophersen, H.P. "Field tests on anchors in clay I: description", Journal of Geotechnical Engineering, 119(10), pp. 1515-1531 (1993).

23. Cho, Y., Lee, T.H., Park, J.B., Kwag, D.J., Chung, E.S., and Bang, S. "Field tests on suction pile installation in sand", Proceedings of the 21st International Conference on Offshore Mechanics and Artic Engineering, Oslo, Norway, pp. 765-771 (2002).

24. Azamathullah, H.Md., Deo, M.C., and Deolalikar, P.B. "Neural networks for estimation of scour downstream of a ski-jump bucket", J. Hydraul. Eng., 131(10), pp. 898-908 (2005).

25. Das, S.K. and Basudhar, P.K. "Undrained lateral load capacity of piles in clay using artificial neural network", Computers and Geotechnics, 33(8), pp. 454459 (2006).

26. Rahman, M.S., Wang, J., Deng, W., and Carter, J.P. "A neural network model for the uplift capacity of suction caissons", Computers and Geotechnics, 28, pp. 269-287 (2001). 
27. Pai, G.A.V. "Prediction of uplift capacity of suction caissons using a neuro-genetic network", Engineering with Computers, 21, pp. 129-139 (2005).

28. Goh, T.C., Kulhawy, F.H., and Chua, C.G. "Bayesian neural network analysis of undrained side resistance of drilled shafts", Journal of Geotechnical and Geoenvironmental Engineering, 131(1), pp. 84-93 (2005).

29. Das, S.K. and Basudhar, P.K. "Prediction of residual friction angle of clays using artificial neural network", Engineering Geology, 100(3-4), pp. 142-145 (2008).

30. Bartlett, P.L. "The sample complexity of pattern classification with neural networks; the size of the weights is more important than the size of network", IEEE Trans. Inf. Theory, 44(2), pp. 525-536 (1998).

31. Vapnik, V.N., Statistical Learning Theory, New York, Wiley (1998).

32. Das, S.K., Samui, P., and Sabat, A.K. "Application of artificial intelligence to maximum dry density and unconfined compressive strength of cement stabilized soil", Geotechnical and Geological Journal, 29(3), pp. 329-342 (2011).

33. Das, S.K. and Muduli, P.K. "Evaluation of liquefaction potential of soil using genetic programming", Proceedings of the Golden Jubilee Indian Geotechnical Conference, 2, Kochi, India, pp. 827-830 (2011).

34. Yang, C.X., Tham, L.G., Feng, X.T., Wang, Y.J., and Lee, P.K. "Two-stepped evolutionary algorithm and its application to stability analysis of slopes", Journal of Computing in Civil Engineering ASCE, 18(2), pp. 145-153 (2004).

35. Javadi, A.A., Rezania, M., and Nezhad, M.M. "Evaluation of liquefaction induced lateral displacements using genetic programming", Computers and Geotechnics, 33, pp. 222-233 (2006).

36. Rezania, M. and Javadi A.A. "A new genetic programming model for predicting settlement of shallow foundations", Canadian Geotechnical Journal, 44, pp. 1462-1473 (2007).

37. Muduli, P.K., Das, M.R., Samui, P., and Das, S.K. "Uplift capacity of suction caisson in clay using artificial intelligence techniques", Marine Georesources and Geotechnology, 31(4), pp. 375-390 (2013).

38. Alavi, A.H., Aminian, P., Gandomi, A.H., and Esmaeili, M.A. "Genetic-based modeling of uplift capacity of suction caissons", Expert Systems with Applications, 38, pp. 12608-12618 (2011).

39. Alavi, A.H., Gandomi, A.H., Mousavi, M., and Mollahasani, A. "High-precision modeling of uplift capacity of suction caissons using a hybrid computational method", Geomechanics and Engineering, 2(4), pp. 253-280 (2010).

40. Gandomi, A.H., Alavi, A.H., and Yun, G.J. "Formulation of uplift capacity of suction caissons using multiexpression programming", KSCE Journal of Civil Engineering, 15(2), pp. 363-373 (2011).
41. Friedman, J.H. "Multivariate adaptive regression spline", The Annals of Statistics, 19(1), pp. 1-141 (1991).

42. Samui, P., Das, S., and Kim, D. "Uplift capacity of suction caisson in clay using multivariate adaptive regression spline", Ocean Engineering, 38, pp. 21232127 (2011).

43. Cheng, M.Y., Cao, M.T., and Tran, D.H. "A Hybrid fuzzy inference model based on RBFNN and artificial bee colony for predicting the uplift capacity of suction caissons", Automation in Construction, 41, pp. 60-69 (2014).

44. Muduli, P.K., Das, S.K., Samui, P., and Sahoo, R. "Prediction of uplift capacity of suction caisson in clay using extreme learning machine", Ocean Systems Engineering, 5(1), pp. 41-54 (2015).

45. Shahr-Babak, M.M., Khanjani, M.J., and Qaderi, K. "Uplift capacity prediction of suction caisson in clay using a hybrid intelligence method (GMDH-HS)", Applied Ocean Research, 59, pp. 408-416 (2016).

46. Castillo, E. and Gutierrez, J.M. "Nonlinear time series modeling and prediction using functional networks: Extracting information masked by chaos", Physics Letters A, 244, pp. 71-84 (1998).

47. Castillo, E., Cobo, A., Gutierrez, J.M., and Pruneda, E. "Working with differential, functional and difference equations using functional networks", Appl. Math. Modeling, 23, pp. 89-107 (1999).

48. Castillo, E., Cobo, A., Gutierrez, J.M., and Pruneda, R.E., Functional Network a Neural Based Paradigm, Springer Science + Business Media, LLC (1998).

49. Castillo, E., Gutierrez, J.M., Cobo, A., and Castillo, C. "Some learning methods in functional networks", Comput. Aided Civ. Infrastruct. Eng., 1, pp. 427-439 (2000b).

50. Rajasekaran, S. "Functional networks in structural engineering", Journal of Computing in Civil Engineering, 18(2), pp. 172-181 (2000).

51. Attoh-Okine, N.O. "Modelling incremental pavement roughness using functional network", Canadian Journal of Civil Engineering, 32(5), pp. 899-905 (2005).

52. El-Sebakhy, A.E., Abdulraheem, A., Ahmed, M., AlMajed, A., Rahajia, P., Azzedin, F. and Sheltami, T. "Functional network as a novel approach for prediction of permeability in a carbonate reservoir", Proceedings of the SPE Conference (2007).

53. Adeniran, A., Elshafei, M., and Hamada, G. "Functional network softsensor for formation porosity and water saturation in oil wells", International Instrumentation and Measurement Technology Conference, Singapore (2009). 
54. Abu-Farsakh, M.Y. and Titi, H.H. "Assessment of direct cone penetration test methods for predicting the ultimate capacity of friction driven piles", Journal Geotechnical and Geoenvironmental Engineering, 130(9), pp. 935-944 (2004).

55. Zhang, W., Goh, A.T.C., and Zhang, Y. "Multivariate adaptive regression splines application for multivariate geotechnical problems with big data", Geotech. Geol Eng., 34, pp. 193-204 (2016)

56. Hastie, T., Tibshirani, R., and Freidman, J., The Elements of Statistical Learning: Data Mining, Inference and Prediction, Springer (2001).

57. Jekabsons, G., VariReg: A Software Tool for Regression Modeling Using Various Modeling Methods, Riga Technical University, www.cs.rtu.lv/jekabsons/ (2010).

58. Math Works Inc, Matlab User's Manual, Version 6.5, The Math Works, Inc., Natick (2005).

59. Kennard, R.W. and Stone, L.A. "Computer aided design of experiments", Technometrics, 11(1), pp. 137148 (1969).

60. Das, S.K. and Sivakugan, N. "Discussion of intelligent computing for modeling axial capacity of pile foundations", Canadian Geotechnical Journal, 37(8), pp. 928930 (2010).

61. Golbraikh, A. and Tropsha, A. "Beware of $q^{2}$ ", Journal of Molecular Graphics and Modelling, 20, pp. 269-276 (2002).

62. Roy, P.P. and Roy, K. "On some aspects of variable selection for partial least squares regression models", QSAR Comb. Sci., 27, pp. 302-313 (2008).

\section{Biographies}

Sumana Bhattacharya completed her MTech in Geotechnical Engineering from National Institute of Technology, Rourkela, India. she also obtained her BTech in Civil Engineering from Jadavpur University, India. Currently, she is pursuing her $\mathrm{PhD}$ degree at Florida International University, USA.

Pavani Murakonda completed her BTech in Civil Engineering from NBKR Institute of Technology, Andhra Pradesh, India in 2012; moreover, she received her MTech, in Geotechnical Engineering from National Institute of Technology, Rourkela, India in 2014. Currently, she is pursuing for $\mathrm{PhD}$ from Indian Institute of Technology, Roorkee, India. Her main areas of research interest include soil structure interaction and artificial intelligence.

Sarat Kumar Das completed his MTech and PhD from Indian Institute of Technology Kanpur, India. $\mathrm{He}$ is a recipient of prestigious Endeavour Research Fellowship by the Government of Australia for the year 2009 for Post-Doctoral research at James Cook University, Queensland, Australia. His areas of interests are geotechnical engineering, optimization methods, artificial intelligence techniques, and material characterizations. He has published more than 60 journal papers and three book chapters. He is a reviewer of more than 50 Journals and the member of Editorial board of two Journals, and theme speaker and session officials of two International Conferences. 